engineering branch, has been concerned with the atomic energy project. The textile section has carried out further work on the rot-proofing of textiles, thermal insulation of protective clothing, the use of synthetic detergents, water-repellants and moth-proofing agents. The corrosion of steel by water is being studied under static and under flow conditions, including the mechanism of corrosion inhibitars. Preliminary data have been obtained on a new type of catalyst for the oxidation of ethylene to ethylene oxide, and an extensive research has been continued on the chemistry of long-chain unsaturated fatty acids. Further work on a new type of propeller de-icing, on the control of frost on standing aircraft, the development of an effective rain repellant for aircraft windows and of a catalyst for the oxidation of carbon monoxide to permit accurate determination of low concentrations in air, promise important peace-time applications. The relation between chemical structure and plasticizer reaction is being studied, while in the aeronautical laboratories the tailless glider was one of the major projects. The hydraulics laboratory completed tests on a model of a Great Lakes' harbour to determine the effect of a proposed pier extension upon sand-bar formation in the harbour entrance. Research on low-temperature lubricants has yielded much valuable information on flow characteristics of greases at low temperatures. Work on artificial limbs has continued in the structures laboratory, making use of processes developed during research on moulded aircraft components. Problems involved in 'panel', or radiant, heating are being investigated, and an important advance in low-cost housing was made in the development of a modular system for the construction of pre-fabricated houses.

\section{BRITISH ELECTRICAL AND ALLIED INDUSTRIES RESEARCH ASSOCIATION}

\section{ANNUAL REPORT}

\footnotetext{
$\mathrm{T}$ HE work of the British Electrical and Allied Industries Research Association throughout the year ended on September 30, 1947, is recorded in the twenty-seventh annual report recently issued.

The field of activity of the Association is perhaps most readily appreciated from a block diagram given in the report, in which twenty-two main lines of research are represented, several of which divide into as many as ten distinct branches. These include extensive studies of insulating and magnetic materials and of gaseous discharge phenomena, in regard to which researches of both a fundamental and of an applied. character are in progress. Surge phenomena, communication interference, earthing safety and circuit problems, overhead lines, power plant and rural electrification are also main subjects of investigation.

In the section on heating, cooking and allied problems, reference is made to work in progress on a heat pump installation and to the early publication of a final report on an experimental investigation of the thermal characteristics of a concrete floor heated by buried cables. In connexion with the work on surge phenomena it is reported that a recurrent surge oscillograph has been developed which employs a
}

sealed-off tube and gives a performance comparable with that obtained with the continuously evacuated type of instrument. Integrating electricity meters provide the subjects of several extensive investigations. A number of these is concerned with the behaviour of instrument jewels, the initiation of a new series of tests on tungsten/diamond and tungsten/sapphire bearings being reported. A detailed examination of the parasitic forces occurring in induction-type watt-hour meters has also been made.

It is interesting to note the wide range of researches supported by the Association in various university departments throughout Britain. These include investigations on the properties of high-pressure, high-temperature steam, work on the fundamental properties of magnetic materials and on the improvement of electrical sheet steels. Studies on the development of spark discharges include an investigation of the build-up of ionization by the Wilson cloud-chamber technique, and work on the highfrequency corona discharge. Experiments on the use of artificial illumination in horticulture are also being conducted in one university department.

In the introduction, the first paragraph deals with the reaction upon the Electrical Research Association of the transfer of the electrical supply industry in Britain to public ownership. The supply industry has provided some 30 per cent of the income of the Association, and the future relation of the British Electricity Authority with the Association is therefore of great importance. It is reported that the chairman of the Authority has confirmed the intention to support the Association and has provided for the safeguarding of the Association's finances during a transitional period in which the new basis will be worked out. The present report testifies to the existence within the electrical industry, both in the supply and the manufacturing spheres, of a spirit of co-operation in research which has built up, by good will and patient effort, a powerful instrument for the scientific and technical advancement of the industry as a whole. Such an achievement is a contribution, by no means inconsiderable, to the vital industrial needs of Great Britain at the present time.

J. G.

\section{$R h$ NOMENCLATURE}

$\mathrm{F}$ OLLOWING the hearing of evidence from interested persons, W. B. Castle, M. W. Wintrobe and L. H. Snyder have reported ${ }^{1}$ to the Surgeon-General of the U.S. Public Health Service on the nomenclature of the anti-Rh typing sera. The report traces the history of $R h$ nomenclature, summarizes the evidence for and against Wiener's and Fisher's nomenclature respectively, and recommends that the Wiener nomenclature shall appear first on the label of serum containers, followed by the Fisher terminology in parentheses, thus: "Anti-Rho (Anti-D)".

The authors have, on the whole, presented a fair and accurate summary of the complex history of the development of $R h$ theory and nomenclature, and of the associated controversies. They have, however, not pointed out that Fisher's notation was put forward $^{2}$ a year or more before any discussion of the possible genetic situations. Fisher's essential contribution lies in his postulation of three pairs of antigens, the antigens of each pair separately behaving as though they were the products of a pair of allelomorphic genes. Neither the validity nor the great 